\title{
Innovations in the Construction Industry: Problems and Potentials
}

\author{
Prasanna Kulatilake
}

\begin{abstract}
Innovation is the means by which an industry progresses taking either big leaps or gradual development. However, the construction industry, compared to other industries such as chemical, electronic, automobile etc, is rather ill equipped for innovations and records a little progress in its main streams of activities; design and construction. While innovation in design may take place even on a project by project basis, in the main stream of construction this seems notably absent.

In this context, the objective of this paper is to discuss such aspects that may arise at various levels within the construction industry and suggest posșible remedial measures. In doing so, the study evolves into three major phases. Al the outset, the term innovation is defined in general terms and then in relation to applicability in the construction sector. The need for innovation in the present day context is highlighted. The key issues related to innovation within the context of the structure of the construction industry and the related extemal factors are discussed at the subsequent stage. The third and the final phase outlines the possible measures that could be adopted in order to overcome such drawbacks as well as to induce the culture of innovation within the construction industry.

In this Study, an attempt has been made to capture the scenario in general, as the issue of innovation in the construction sector is common to almost any country situation. The recommendations too are made general, which could however be adopted to suit the specific situation where appropriate. Although the situation of Hong Kong has been taken into discussion for illustrations, the issues raised are common to the Construction Industry in many parts of the world.
\end{abstract}

\section{INTRODUCTION}

It is Man's incessant desire for novelty, efficiency in terms of time and cost, and better quality of life that has motivated for innovations related to all spheres of life. Innovation is the result of creative thinking pursued in terms of action, manifesting in what we may call an invention. However, Innovation is not either an entirely a new phenomenon or an action. Rather, it is a re-organization of ideas or actions in a way that has never been done before so that its outcome generates a similar effect.

Definitions of innovations are numerous and differ depending upon the field of activity in which innovation occurs. In terms of the construction industry, Dulaimi (1995) provides us with a very fruitful definition to understand the nature of innovation. He suggests that innovation is the effort to create a purposeful, focused change in the economic or social potential of an enterprise. Thereby he emphasizes the economic dimension that is closely associated with innovations particularly in the construction industry. According to Tatum (1987) however, innovation stems primarily from two forces; namely, the market demands and the progress at the technological and scientific frontiers. Without any question, research and development play a significant role in initiating innovations leading to achieving higher levels of efficiency and productivity that have become pressing demands.

The impetus for innovation always stems from the rigorous constraining factors in a particular field or a situation. In fact, they in turn become blessings in disguise, facilitating movements forward and widening the horizons of the respective fields. Emphasizing this view, Ganesan (1996:99) states that innovation in construction is a competitive response to the constraints of the industry and economy to achieve more efficient procurement, production and completion of projects within the limitations of resources, particularly labour and materials.

He stresses the inextricable link between the construction industry and the economy, where the key phases of a construction project such as procurement. production and completion become essential resources. However, they may become constraints for innovation in the context of labour and materials. The dynamic character of other industries and the economy, client requirements and project conditions can indeed become additional interrelated factors that facilitate innovation. 
Defining innovation as 'the process by which a new idea is discovered or created' 'Tatum (1987), identifies two facets of the concept. One is the process innovation, which signifies advances in technology that enable a greater output per unit of input and the other is the product innovation that results in a qualitatively superior product. Dulaimi (1995) takes the same stand when he refers to innovation that produces greater volume of output as process innovation and, one which facilitates a qualitatively superior output from a given amount of input resources as product innovation. As such, innovation may be a flash of genius thought and action or it may be the innovative use of existing technologies or processes to meet new demands.

Today, the demand for innovation is increasingly felt due to a number of reasons. As noted by Ganesan (1996:100), they include the demand for higher productivity' rising construction costs, higher building demands in terms of volume and the quality of construction. The increasing pace of modern life that demands speedy completion of projects also makes the need for innovation a strong, compelling pressure in contemporary construction practice.

However, the construction industry has unique characteristics, which often slow down the process of innovation. It is widely accepted (Pries and Janszen, 1995; Westling, 1991) that compared to other industries such as chemical, electronic, automobile etc. construction sector lags far behind in the aspect of innovation due to a variety of reasons.

\subsection{Innovation in the Construction Industry: The Major Constraints}

The constraints inherent to construction industry with respect to innovation arise primarily from its structure itself. Added to this also come from the associated external factors intrinsic to its operations.

\subsection{The Structure of the Construction Industry}

The very structure of the construction industry poses limitations on innovation, the key points of which are discussed briefly below:

\subsubsection{The Fragmented Nature}

\footnotetext{
' especially in the context of labour shortages (referring to Japan and Hong Kong), material and energy resources
}

The Construction is an assembly industry. It is basically segregated into two key phases as design and construction. This division is especially significant in the traditional building process, where the two phases are mainly handled by two sets of teams. In this process, an architect assisted by one or more consultants, produces a design for a client. Drawings are drawn in detail, specifications are given, and a contractor executes the design assisted by suppliers and sub-contractors. Because every project is unique, there is little reason for a contractor to invest in innovation, other than the optimization of their own process. There are neither economies of scale nor learning effects (Pries et al 1995:44).

A study conducted by the UK Chartered Institute of Building (1995) reveals that on the builders side, there are several reasons which obstruct innovation. They include, unwillingness to change, fear of failure due to high insurance costs and guarantees, heavy reliance on sub-contracting, very limited opportunity for the builders to influence the design, competitive tendering etc.

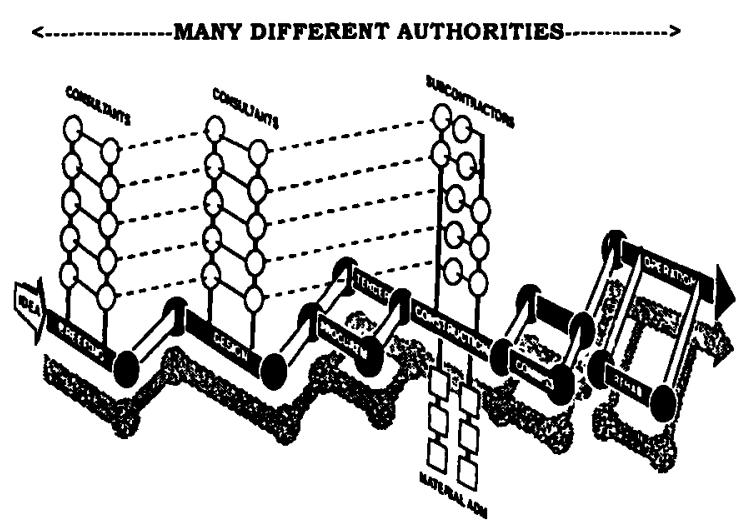

Figure 1: Fragmentation of the construction process, division into stages and occupational groups - circles and squares symbolize limits of responsibility (Source: Westling.1991:31)

Love and Skitmore (1997) referring to both the traditional and non-traditional procurement strategies too stress on the gap between design and construction, which in turn has led to major behavioural, cultural and organisational differences between project individuals and groups. They single out the resultant major drawback as the potential communication gap. In most situations, the clients often receive less than optimal design solutions as contractors are kept apart from the decision-making processes of the design team'. 
Also, the tendency of functional disciplines to operate independently is very high in the construction industry. Often decisions are made without considering their impact on other disciplines.

\subsubsection{The Client's Domination}

More than in other-industries, the client plays a major role, especially with respect to buildings. After all it is he who commissions a project. Rather than being just buyers of finished products, the owners are often major participants in the projects particularly in the building and heavy sectors of the construction industry. Nam and Tatum (1997) highlight that they establish the mechanism by which the involved parties communicate and collaborate, make decisions on important technical matters throughout the project execution and sometimes share a high proportion of the risk. As such, the owner's readiness for novelty, willingness for taking risks, and even level of sensitivity and technical awareness become quite important for better results in construction innovation.

However, in many circumstances, the client stresses on the need to lessen the risk factor as the products have a very long life span. He prefers to stick to proven methods especially in terms of durability and quality, and avoid radical changes. This greatly reduces the triability or the ability of a buyer to try a new product and ease of replacing it if it is unsatisfactory (Pries and Fanszen, 1994). In fact, depending on the readiness, commitment and attitude, the domination of the client may be a constraint or a positive factor.

\subsubsection{Uniqueness of Projects}

Compared to automobile or electronic industries, the possibilities for repetition are much less in the construction industry. Also the products are essentially location- bound, and thus are subject to unique sets of constraints imposed by their very locations. They can be clearly distinguished as buildings, bridges, tunnels, roads etc. All these in turn become obstacles as the applicability of a particular innovation to a great number of products becomes less.

\subsubsection{Heavily Dependent Nature}

As explained earlier, construction is an industry of assembly. The building materials as well as machinery and equipment come from various suppliers and sub contractors. As Cooper (1997) adds, much technical change aimed at improving products or reducing costs is embodied in inputs acquired from suppliers, thus reflecting the Research and Development (R\&D) work carried out by them. He further goes on to say that in contrast to many other assembly industries such as automobiles or aerospace, construction firms are relatively small and suppliers are relatively large. Construction firms are heavily dependent on technical developments deriving from suppliers. Many construction firms do not have the technical competence to cope with new technologies or carry out research \& development. Even in cases of large construction firms, in reality they are a collection of small enterprises, each of which in the short term, has to maximise profit and minimise risk (Westling, 1991).

Citing a study done in the Netherlands, Pries and Janszen (1995) point out that more than $70 \%$ of innovations come from the supply industry (within the construction industry and external).

Over $80 \%$ of all product innovations have originated from the supply industry, and thus conclude that it has the dominant role over innovation within the construction industry (see Table 01)

\begin{tabular}{|l|c|c|c|}
\hline & All Innovations (\%) & Process Innovations (\%) & Product Innovations (\%) \\
\hline Contractor & 7.5 & 14.6 & 2.9 \\
\hline Supplier & 72.4 & 56.2 & 82.7 \\
\hline Architect & 0.9 & 2.2 & 0.0 \\
\hline Consultant & 11.4 & 16.9 & 7.9 \\
\hline Miscellaneous & 7.9 & 10.1 & 6.5 \\
\hline
\end{tabular}

Table 1: Types of Innovations and attribution to a Party (Source: Pries and Janszen, 1995:46)

\footnotetext{
${ }^{2}$ However, in tumkey contracts this gap is considered to be lessened to a significant extent as a project from its inception to completion is mainly handled by a single contractor and also as the project manager co-ordinates the work among different sub groups.
} 


\subsection{Related External Constraints}

\subsubsection{Governmental Regulations}

The construction industry today is dominated by very severe price competition. However, this market becomes somewhat unique, as it is subject to certain types of regulation, which are imposed by the government. Thus the government exercises a definite influence on the construction market through the mechanisms as shown in the Figure 2 below:

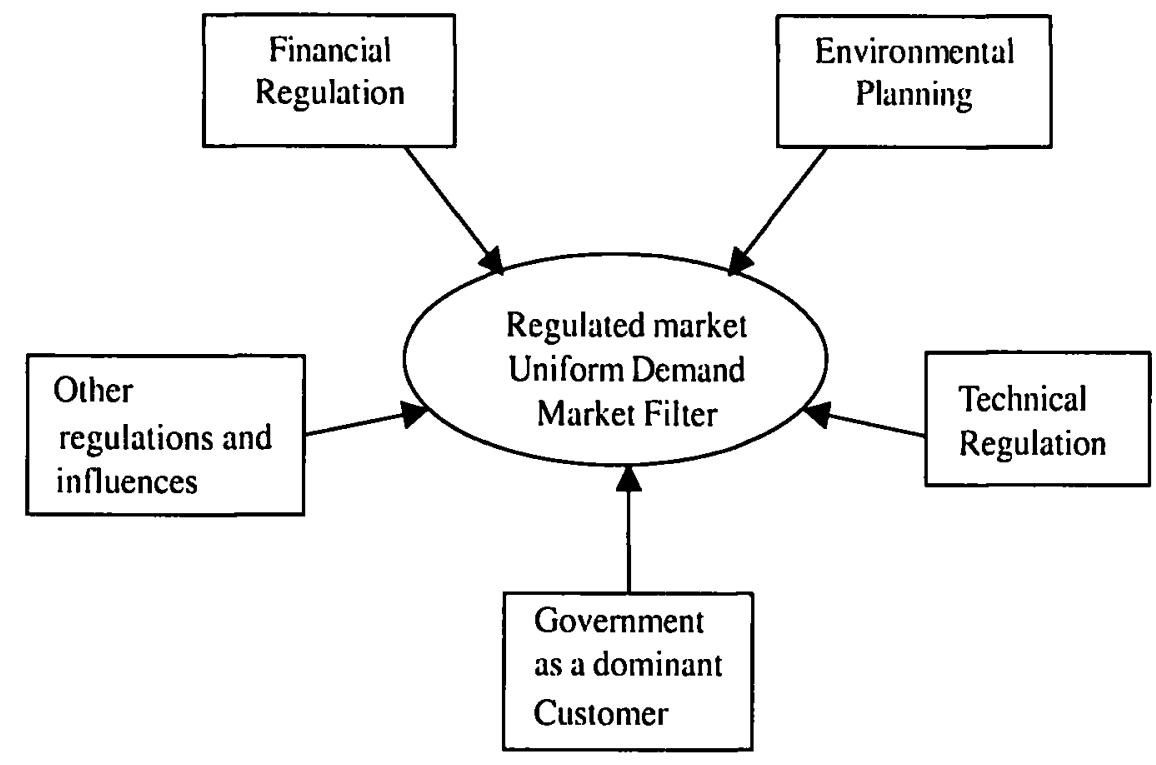

Figure 2: The influence of the government on the construction market (Source: Adopted from Pries and Janszen, 1995:46)

As Pries and Janszen (1995) discuss in detail, the technical regulations determine the quality for a major part of the production in the construction industry. In addition, environmental regulations too are of growing importance and they can be seen to influence what is done and what is accepted in the pursuit of safe practices.

\subsection{The Context of Hong Kong}

Hong Kong has developed into a major commercial centre of the Southeast Asian region today, with the contribution of the property and construction sectors to GDP amounting to $22 \%$ (Tam,1997). Its steady economic growth and the demands of the affluent society for buildings of higher quality, together with the growing complexity and the magnitude of construction projects demand changes and innovative approaches in the overall mechanism of the construction sector.

Nevertheless, many of the factors discussed earlier are common to Hong Kong too and continue to hamper innovation. In addition, there are some key constraining factors, which Hong Kong finds itself entangled in. that deter potential innovation. They include environmental impact regulations, schedule constraints and budget restrictions as well as very restrictive and challenging site situations in urban settings, reclaimed land and mountain slopes (Ganesan, 1996:100). In addition, extremely high land values demand cost effective construction technologies in order to keep overall project costs at bay. Without doubt, these impose restrictions on initial innovative endeavours. For example, Mo and $\mathrm{Ng}$ (1997) highlight the drawbacks predominantly traditional procurement systems that still prevail there. According to Tam (1997), the construction systems in Hong Kong are still conservative. He adds that people in the industry are quite reluctant to change and are less inclined to accept new ideas unless they are well tested in all other regions. Thus it is not unusual that the procurement method used in Hong Kong is still very conventional. The system typically involves an architect to produce a design followed by the appointment of a contractor who oversees the administration of the project.

\subsection{FACILITATING INNOVATION: THE KEY FACTORS}

\subsection{Procurement System}

As explained earlier, the first major drawback to innovation is the lack of integration between design and construction phases of the construction industry. This is an inherent drawback prevailing in the traditional procurement system. To remedy this, new procurement 
systems have to be introduced. The popular Turnkey or Design-and-Build (D\&B) is one such system.

It is argued most often that Design \& Build brings the designer and the contractor together to develop detailed designs that can improve buildability and minimise the possibility of the project manager going wrong (Tam, 1997). Also it facilitates a single point of responsibility for the client. The advantages of this method in fact include shortening of lead times, involvement of the contractor in the design process, greater price certainty, improved communication and reduced construction time (Anumba et al, 1997). On the one hand, it helps in lowering interest payment ${ }^{1}$ and on the other, it enables quick utilisation of the capital, minimises the effects of inflation ${ }^{2}$, reduces disputes and likely arbitration, and provides better value for money (Tam, 1997). For these reasons in Hong Kong, D\&B is quite popular. However, It is more applicable to simple and standadised building projects (Mo and $\mathrm{Ng}, 1997$ ) and may not provoke innovation in a notable way.

At the same time, the D\&B method has a number of disadvantages too. This includes reduced design quality, inhibition of changes by clients, high tendering costs (Anumba et al, 1997), limited flexibility to project management, and increased risk for client with single point of responsibility (Mo and $\mathrm{Ng}, 1997$ ).

It is noteworthy that an approach known as "Concurrent Engineering"(CE) has emerged with the view to overcome the drawbacks of the D\&B. Also known as Simultaneous Engineering or Parallel Engineering, this approach has resulted from ever-increasing pressures on manufacturers to be more competitive in terms of product quality, cost and durability and more responsive to change (Anumba et al, 1997). It is also noteworthy that, the concept of $\mathrm{CE}$ is to bear all the concerns throughout the product life cycle concurrently during product design. The strategy of concurrence provides an opportunity to address the source of conflicts between design agents.

\subsubsection{Contract Documentation}

If changes in the procurement system are to take place, the contract documentation also has to undergo change. Conventionally, such a document generally contains the terms and conditions of the contract, specifications and construction drawings and bills of quantities.

In the case of D\&B contracts, the contractor has to produce his own set of measurements. In order to facilitate innovation, special provisions could be made in the insurance and guarantees that they do not inhibit the motivation for innovation, which automatically involves a fair amount of risk. The aspect of specification also has to be carefully scrutinised, in the context of innovation.

\subsubsection{Innovative Design Competitions}

One of the major drawbacks present in today's procurement system is the accepted criteria adopted to select a contractor. The tendency most often is to select the lowest bid in many circumstances. However, the heavy emphasis given to the cost aspect in such selections is most likely to push innovative approaches aside. Thus selection criteria, promoting innovation should include a balanced system of appreciating cost factors as well as, design appropriateness, and innovative approaches. This would encourage the innovative contractors to take risk and put forward their proposals in a more effective and creative manner.

Design competitions at the same time induce teamwork, and integration. As McLeish (1994) explains, one of the main advantages in the competition arrangement is that the architect, the design engineer and the construction team have to develop their own interests on a more collaborative basis. Competition also provide the impetus for new, and creative thinking always as it gives a wider choice for the client to select the best alternative among a number of competitors. What is important here is to make the selection criteria on the basis of overall appropriateness in the design as discussed above.

\subsection{Organisational Size and Structure}

The $D \& B$ and the $C E$ in turn necessitate the restructuring of the organisational structure of the whole sector. For instance, the larger firms are more able to afford the investment for innovation and more able to tolerate the risk of adoption. On the other hand smaller firms are more likely to value technology and to use simpler decision-making processes. Thus their organisational size may be related to the effectiveness of the innovation process (Nam and Tatum, 1997).

The Japanese model in this regard provides a good example, which is often referred to as Big Five or Big Six. These construction firms are conglomerates of various horizontal and vertical industrial connections (Pries and Janszen, 1995). Over 50\% of their work is

\footnotetext{
${ }^{3}$ The land values are extremely high in Hong Kong.

${ }^{4}$ This results from a shorter procurement duration.
} 
obtained on a non-competitive negotiated basis, the greater part of it coming from the private sector. In these, it is notable that D\&B account for $25 \%-35 \%$ of the total (Ganesan, 1982:162) work undertaken.

However, within a construction firm, organisational structures should be changed to facilitate these structural changes. At Shimizu Corporation, one of the Big Six, in Japan cited above, integration of design and construction reduces the time required to receive building permits. Also, 'parallel development' of working drawings allow construction schedules to be planned at the schematic design stage and construction to begin before construction documents are complete (Ganesan, 1996:102).

\subsection{Management}

Management is yet another key aspect that contributes to innovation. As essentially the whole process of design and construction and thereby innovation is teamwork, management has a key role to play. It is no secret that the management at each level of a construction organisation is responsible for integrating and maintaining general and individual technology levels (Ganesan, 1996:103). Referring to process innovation, Lahdenpera et al (1997) highlight the need for continuous improvement involving management. He further identifies the focus of continuous improvement as,

- Eliminating bottle necks

- Variability reduction

- Cycle time reduction

- Elimination of non value-adding steps from the flow

- Ongoing consideration of customer requirements for each activity

- Fine-tuning different parts of the process for better synchronisation

- Maintenance for better reliability, and

- Incremental development of equipment.

\subsection{Research and Development}

It is undeniable that research and development (R\&D) play a vital role in the entire process of innovation. As the potentials for innovations lie always in aspects related to construction, such as building materials, equipment and machinery, structural systems, design principles, management, design tools such as computer software, etc. R\&D have to be facilitated within a construction firm as well as within those associated supplier and subcontracting organisations.
At the same time, various policy measures have to be also taken at the National level, in order to facilitate research. Government budgetary allocations, and as a policy to recognise the validity of research are also needed. Through various research grants, education institutes and universities could be geared to research, and they can be linked with construction sector organisations in order to ensure their applicability and practical relevance. Needless to say, provision of a comprehensive database, training of personnel at different levels, continuous professional development (CPD) programmes become quite important in this regard.

\subsubsection{Information Technology (IT)}

In the construction industry, IT is creating new possibilities and as a result its advancement is placing new demands upon construction organisations. In fact, it can effectively promote integration within the industry. Unlike the past where it was used merely for improving traditional business procedures Information Technology in the present day context plays a much wider role as an innovative agent. It enables new and different alternatives to organising and operating business enterprises (Ahmad, 1995). This has in turn posed the business organisations with new opportunities as well as challenges.

The dynamic nature of the construction processes, interdependence of its various elements, and the need for teamwork, flexibility and co-ordination have widened the scope of information technology within the construction industry. Its multiple usage can be cited as communication, data accessibility, and common systems designed to produce data. Ahmad (1.995), cited above goes on to say that IT implementation is not just a technical enhancement, but a managerial decision that involves re-engineering of organisational functions and operations. It is therefore clear that there is a great potential of employing IT, in the process of innovation.

\subsection{Technology Transfer}

Technology transfer facilitates spread and use of a particular innovation. It is not always possible for a firm or the construction sector of a particular country to make new innovations. As such, transfer of technology from other countries who have well developed systems, and their possible adaptations are quite important aspects to be explored. 
In the case of Hong Kong, this can well be adopted, as the possibilities for original research are comparatively less. Thus technology transfer in terms of building processes, design principles, construction methods, building materials, etc could be envisaged to facilitate innovation.

\subsection{Planning and Design}

'Planning and design involve the most critical decisions concerning the resources and cost of a project. and have therefore by implication a high impact on construction productivity. It has been estimated that designers control $70 \%$ of project costs and that planning and design is the single most important level for the construction productivity' (Ganesan, 1996:105). Increased levels of productivity on the other hand, reduce the unit cost, and thus give an innovation the much-needed cost-effectiveness.

Planning and design entail project planning from the inception to completion, utilisation of resources such as, man-power, machinery and equipment, materials as well as the selection of most appropriate design principles and methods in terms of time, cost and quality. Thus essentially this level provides the best ground for the seeds of new thinking and innovative approaches.

\subsection{Construction Systems and Methods}

Construction systems and Methods illustrate the thinking process of the planning and design stage more elaborately. A great variety of new construction systems are being used today in the construction industry over conventional systems. Interestingly, in Hong Kong, there are major construction projects that has adopted latest construction systems and methods. They include, the Cross Harbour Tunnel completed in 1972; probably the world's first example of a modern build-operate-transfer project (BOT) (Smith and Wilkins, 1997), the head quarters building for the Hong Kong Bank, the Mass Transit Railway, new airport at Chek Lap Kok, Western Kowloon Reclamation etc.

In addition to the use of new cost efficient construction systems, they also envisaged new procurement systems such as design and build and joint ventures. All these have in turn facilitated innovation as well as adaptation of innovätions.

\subsection{Equipment and Machinery}

Equipment and machinery too contribute to a substantial share of cost in the construction industry. A wide range of advanced machinery that employs new technology is being used in the industry today both for the substructure and superstructure works. A lot of innovations have been made in this respect too, and the space for innovations is ever on the increase. Robotics construction machinery is the latest available in this respect and is being used in most applications. The benefits of the same are cited by Ganesan (1996:110) as follows:

- Increase in productivity through automation of repetitive processes

- Elimination of work in dangerous or inaccessible locations such as underground, underwater and high levels

- Reduction of direct contact with hazardous materials and products

- Detection of maintenance work required and subsequent repair

- Elimination of additional and intermediate equipment such as scaffolding

\subsection{Materials and Products}

Quite a number of new materials (High performance concretes and very high performance concretes, Autostress steel etc) and products for both the exterior and interiors of buildings and other construction projects have been innovated worldwide in recent times (Ganesan, 1996:111-A 113). They have a variety of advantages over the conventional materials and products such as quality, durability, strength, reduction of labour required, increased building performance -etc. These can be adopted in various country and project situations depending on their applicability.

\subsection{CONCLUDING REMARKS}

'Innovations also require and encoyrage innovation' (Ganesan, 1996:100), thus making the process cyclical and futuristic. Ever increasing market demands, higher quality in life etc. on one hand and the constraining factors such as rising costs, labour shortages, and speedy completion of projects have all intensified the need for innovation.

This paper highlighted that innovations happen and are needed throughout the entire processes of design and construction irrespective of the nature of the project. Also it is equally important to adopt innovations 
developed in other countries quite apart from originating innovations. Such approaches are at times more appropriate where there are noconducive environments for innovations, and also when such efforts become unaffordable!

Innovations by very nature involve a fairly high risk factor and as the construction projects have very long life spans, the opportunities to test their applicability are limited. As such especial attention and emphasis should be given in making innovations that are viable in terms of time, quality and cost. It is however unde-

\section{REFERENCES}

Ahamad, I.U et al.(1995) Information Technology(IT) and Integration in the Construction Industry". Construction Management and Economics, Vol. 13, pp 163-171.

Anumba, C.J et al.(1997) "Concurrent Engineering in Design Building Projects",

Construction Management and Economics. Vol. 15, pp 271281.

Bjork, B.C (1997) "A Framework for Discussing Information Technology Applications in Construction", CIB Proceedings Publication 208, Queensland, Australia. pp 9-11.

\section{Civil Engineering Research Foundation (1996)}

Action Plan: An Enhanced Building Technology Evaluation Process, CERF, USA.

Cooper, I. (1997) "The UK's Changing Research Base for Construction: The impact of recent government policy", Building Research and Information, Vo. 22, No.1, pp.3439.

Ganesan, S. et al (1996) Construction in Hong Kong, Avebury Ashgate Publishing Ltd.. Hong Kong

Mcleish, C (1994) " Improved Quality Control Through Innovative Design and Construction Competition", Building research and Information, vol. 22, No.1, pp 34-39.

Dulaimi, M (1995) “ The Challenge of Innovation In Construction", Building Research and Information, Vol 23, pp 106-109.

Pries, F and Janzen, F (1995) "Innovation in the Construction Industry: The Dominant Role of the Environment". Construction Management and Economics", Vol. 13, pp4351.

Procurement: A key to Innovation (1997) "Links Between Innovations in Performance Measurement and the Provision of Facilities with Innovative Technologies", I.F. Research Corporation, Montreal, pp 51-60. niable that innovation cannot wait until all such obstacles are overtaken, because it is only by trial and error that the world has come this far, to the level of development that it has reached. It is innovation, and quite bold risk taking innovations that has changed human life from the primitive to the modern and unless and until innovation becomes a central tenet of the construction industry, it will remain locked up in its own trap of conventional safe practice. It is time to take a hard look at our construction industry and ask ourselves how we may promote innovation so that we can reach further ahead.

"The Tendering Contract: Fairness, Equality and innovation", I.F. Research Corporation. Montreal, pp 91-100.

Should We Strive For Innovation or Just run Our Projects well?", I.F. Research Corporation, Montreal, pp 333-344.

"An Innovative Incremental Approach For Intelligent Authoring of Construction Activities", I.F. Research Corporation. Montreal, pp 369-374.

"Toward An Innovative Procurement Process For Construction",I.F.Research Corporation. Montreal, pp423-432.

"Design and Building Procurement Method in Hong Kong- An Overview", IF Research Corporation, Montreal, pp 453-462.1

"Construction Joint Venture In Hong

Kong”, IF Research Corporation, Montreal, pp 535-544.

"Procurement Sirategy, Innovation and Assessment of Project Successes", IF Research Corporation, Montreal, pp 703-710.

"Design and Building For a Complicated Re Development Project in Hong Kong: The Happy Valley Racecourse Development", IFResearch Corporation, Montreal, pp743-750.

Innovation In Procurement- Why, and to where? Questions for Research", IFResearch Corporation, Montreal, pp781-787.

Westling, H (1991) Technology Procurement: For Innovation in Swedish Construction, Swedish Council for Building reseirch, Stockholm. 